\title{
PESQUISA SOBRE PAISAGEM URBANA, DIVERSIDADE E ADEQUAÇÃO AO RELEVO NATURAL DO COMÉRCIO DE PEQUENO PORTE - INDICAÇÕES PARA AVALIAÇÃO DE LEIS DE USO E OCUPAÇÃO DO SOLO
}

\author{
URBAN LANDSCAPE RESEARCH: URBAN COMMERCE AND THE LOCATION OF ACTIVITIES \\ IN THE CITY
}

\begin{abstract}
AMARO, João Júlio Vitral
Doutor pela Technische Universitaet-Berlin, Alemanha, Departamento de Urbanismo - Escola de ArquiteturaUFMG.E-mail: vitral@arquitetura.ufmg.br
\end{abstract}

\section{RESUMO}

O texto aborda a questão da paisagem urbana e a natureza interdisciplinar das pesquisas relacionadas com a localização de atividades na cidade. Tomando como exemplo o caso da distribuição do comércio de pequeno porte na cidade, procura-se apontar a interação dos vários fatores envolvidos na escolha da localização. Com o conceito de "diversidade" é indicada a interdependência sistêmica entre vários elementos que contribuem para caracterizar as vantagens da proximidade das diversas atividades urbanas. Procura-se mostrar ainda a abordagem econômica como uma das possibilidades da análise do comércio urbano, centrando a atenção em duas de suas vertentes teóricas. A limitação de ambas consiste em tratar muito esquematicamente o conceito de "mobilidade". Procura-se enfatizar que "mobilidade" é uma categoria central para se analisar a localização de atividades econômicas e, com isso, o caráter singular e único de cada cidade. São apontadas ainda as implicações do relevo natural para o assentamento das atividades e para a percepção pelos habitantes das diversas características dos lugares na cidade.

Palavras-chave: Paisagem, comércio urbano, diversidade, interdisciplinaridade.

\begin{abstract}
The present research approaches the question of the urban landscape and the interdisciplinary nature of research related to the localization of activities in the city. Taking as an example the case of the distribution of the small commerce in the city, this paper aims to point the interaction between some of the involved factors in the choice of the localization. With the concept of "diversity", the indicated systemic interdependence between some elements contributes to characterize the advantages of the proximity of the different urban activities. The Author also aims to show the economic approach as one of the possibilities of the analysis of the urban commerce, focusing the attention in two of its theoretical sides. The limitation of both consists of dealing too schematically with the concept of "mobility". The Author intends to emphasize that "mobility" constitutes a central category to analyze the localization of economic activities and, consequently, of the singular and unique character of each city. The implications of the natural relief are also mentioned with respect to the settlement of the activities and the perception by the inhabitants of the various and different characteristics of the places in the city.
\end{abstract}

Key words: Landscape, urban commerce, diversity, interdisciplinarity.

O ensino e a pesquisa relacionados à "paisagem" envolvem uma prática interdisciplinar, uma abordagem na qual os diversos saberes se coordenam e se subordinam à consideração de um conjunto ou totalidade de fatos ou eventos. Isso porque a idéia de "paisagem" envolve a noção de "sistema", de articulação de "elementos" (naturais e construídos) sobre um território, onde a alteração de uns implica a alteração de outros ${ }^{2}$. A tradição geográfica alemã recorre à noção de "paisagem" (Landschaft) para designar superfícies do planeta onde ocorrem interações nos encontros de comunidades humanas e espécies naturais. Humboldt se referiu a Landschaft como 
a totalidade de uma porção da superfície terrestre: uma paisagem determinada é aquela unidade espacial em que o conjunto formado pela capacidade produtiva, a conformação física e o uso diferem de outras unidades espaciais.

Assim, pensar a cidade como "paisagem", ou pensar o desenho ou projeto da paisagem urbana consiste em considerar a articulação que se estabelece entre as partes de um sistema - considerando que as partes articuladas emprestam à paisagem uma personalidade própria que a difere de outras -, visando a uma situação de antemão julgada desejável. Da concepção inicial ao projeto definitivo para intervenção em elementos naturais e culturais (os elementos construídos), esbarra-se, com freqüência, devido à complexidade das questões envolvidas, em alguns problemas metodológicos. Se a generalização do discurso ambientalista nas duas últimas décadas tem, por um lado, gerado uma considerável quantidade de estudos sobre os efeitos não desejáveis da ocupação da paisagem construída, não tem havido, por outro lado, uma sistematização suficiente para suscitar uma interpretação mais integrada por parte dos que se interessam ou podem conduzir o desenvolvimento urbano, regional, ou de alguma outra porção qualquer da superfície habitada. As intenções explicitadas no discurso ambientalista muitas vezes não têm conseqüências nos métodos de investigação: a política ambientalista tem por divisa o "pensar global com atuação local", deixando, no entanto, uma grande carência no que diz respeito às interações inerentes ao objeto de intervenção como totalidade sistêmica.

As dificuldades na consideração do "sistema-paisagem" aparecem logo de imediato no confronto suscitado pelos instrumentos de gestão de um território. Há, quase sempre, subjacentes aos instrumentos de gestão, idéias raras vezes explicitadas sobre o objeto-alvo das medidas adotadas, que tornam mais complexa a coordenação de ações de planejamento. Tais dificuldades são evidentes quando são introduzidas as questões relativas aos custos envolvidos; por exemplo, os custos inerentes à perda dos bens naturais. Considerando que as diversas formas de gestão ambiental implicam a ponderação dos custos envolvidos para as melhores alternativas econômicas por ocasião do consumo dos bens da natureza, as decisões sobre o melhor uso dos recursos naturais são, na maioria das vezes, decisões exclusivamente econômicas; ou seja, as estratégias de gestão se pautam, invariavelmente, pelo cálculo econômico. Mesmo quando as estratégias estão centradas nas restrições do uso econômico de alguns bens naturais (determinadas reservas minerais, espécies arbóreas das florestas, exemplares da fauna etc.), os argumentos seguem a lógica da demonstração econômica: quanto seria, por exemplo, o prejuízo futuro pela perda das reservas florestais? Quais os custos futuros para a disponibilidade da água se a degradação ambiental provocada por novos loteamentos compromete os mananciais? Porque a abordagem puramente econômica no trato das questões aqui envolvidas implica um reducionismo descabido, são prementes as considerações de ordem metodológica.

Com a crescente difusão de textos sobre meio ambiente, atribuímos prontamente à palavra "diversidade" uma qualificação positiva. Sobretudo para o jargão dos profissionais que lidam com meio ambiente e cidades, "diversidade" tem uma história cujas raízes remontam ao livro de Jane Jacobs The death and life of greath American cities ${ }^{3}$. Não é intenção deste autor repetir aqui teses já expostas por Jacobs, nem insistir nos conceitos já trabalhados por ela, mas tão somente, a partir de alguns elementos implícitos em sua obra, possibilitar uma leitura do espaço urbano atenta à lógica de localização das atividades comerciais. Para não adiar mais o tratamento do tema aqui proposto, pode-se supor que o leitor de The death and life... já sabe, pela ênfase ali dada sobre a "diversidade", que o comércio urbano tem um papel fundamental na fruição da paisagem urbana 4 . A localização comercial e a "diversidade" nela implicada são relacionadas com as determinações de ordem física. Seja pela extensão dos lados das quadras (que nas ruas de comércio possibilitam mais esquinas e, com isso, maior número de lojas), seja pela declividade das vias que possibilitam diferentes modalidades de deslocamento (diferenciando, assim, as atividades comerciais), os condicionantes físicos orientam a distribuição das atividades de comércio. 
A lógica da distribuição das atividades urbanas ou as regularidades encontradas na localização dos diferentes usos urbanos serão o alvo - sobretudo no que diz respeito ao comércio urbano - das investigações visando oferecer subsídios para a melhor (mais eficiente quanto à proximidade dos fluxos de deslocamento, mais adequada à vizinhança, menos agressiva do ponto de vista estético-paisagístico etc.) localização. O planejamento urbano, como qualquer outro tipo de planejamento, pode ser entendido como um conjunto de ações encadeadas visando estabelecer relações de causa e efeito, tendo em vista um resultado específico desejado. Desse modo, o planejamento urbano, mediante seus planos urbanísticos, traz, de forma explícita ou não, um modelo onde se privilegia aquilo que é passível de ser ordenado. Os modelos não são simples retratos ou tipificações de situações existentes, mas interpretações das regularidades, das interações entre causas e efeitos presentes nos casos estudados e aplicáveis em casos semelhantes. Isso significa que aquilo que não é passível de ser ordenado não tem lugar nos modelos.

Centrando mais na questão da localização comercial, pode-se verificar na literatura sobre o tema que há duas vertentes explicativas para o uso e ocupação do solo urbano. Uma delas é representada pelos chamados "modelos de localização" nos quais a "distância ao centro" é o fator preponderante. A outra vertente tem na teoria da renda fundiária da economia clássica sua fonte de inspiração. A primeira tem em von Thünen um precursor. $\bigcirc$ exame feito por von Thünen dos tipos de plantações nos estabelecimentos agrícolas concluiu que alguns tipos de produção são condicionados à distância ao mercado (o centro de convergência de todos produtos, no modelo de von Thünen). Isso porque os custos de deslocamento entram como um componente dos custos de produção dos produtos agrícolas, fazendo uns produtos mais viáveis que outros. Esse modelo de von Thünen, adaptado ao caso urbano, procura retratar as condições de localização das atividades econômicas: quanto mais próximas ao centro, menores são os custos de deslocamento e maiores os preços dos aluguéis.

Pretendendo estar situada no pólo oposto e oferecendo uma alternativa (menos formalista, não quantitativa) aos modelos baseados em von Thünen, a literatura especializada conta com as teorias derivadas dos debates, sobretudo na Inglaterra dos séculos XVIII e XIX, sobre a questão da propriedade fundiária, agrupadas sob o nome de teoria da renda fundiária. A vertente inspirada na teoria da renda fundiária da economia clássica procura também fazer uma adaptação. $\bigcirc$ problema enfrentado pelos economistas ingleses no início do século XIX era, a partir dos diferenciais de fertilidade, apresentar a base explicativa para a regularidade da formação dos preços dos aluguéis e, por conseqüência, do preço da terra ${ }^{5}$. Mas uma adaptação da teoria, no intuito de decifrar as diferenças dos aluguéis na cidade, não pode se referir a diferenciais de fertilidade. Os espaços urbanos, no entanto, diferenciam-se por "produtividades" (ou rentabilidades 6 ) distintas. Assim, os maiores sobre-lucros no espaço urbano - no caso do uso comercial - são proporcionados pelas maiores velocidades de venda. Na adaptação do modelo, "fertilidade" se transforma em "velocidade de vendas"7. Assim, aqueles lugares que proporcionam maiores velocidades de vendas podem auferir maiores ganhos.

As duas vertentes explicativas que procuram adaptar as teorias da renda fundiária rural carecem, no entanto, do exame mais acurado de um elemento que é comum a ambas: o "deslocamento". As duas vertentes abordam a questão do deslocamento com um inconveniente reducionismo econômico. Por isso mesmo, convém observar que a consideração das modalidades de deslocamentos não se reduz a uma mera questão de custos de deslocamento. Por considerar apenas aquilo que é essencial (ou considerado válido para grande número de casos), os modelos de localização urbana, em geral, excluem alguns elementos fundamentais, como o relevo do sítio onde está assentada a cidade ${ }^{8}$.

Relevos distintos oferecem "espaços cênicos" distintos e alguns deles indicam, acolhem e favorecem o encontro de compradores e vendedores. O futuro da localização comercial em uma cidade, em suas dimensões funcionais ou semânticas, vai depender, em grande parte, das decisões que 
remontam à época da sua fundação. A escolha do sítio natural e o traçado da malha urbana vão definir as características ou a personalidade ${ }^{9}$ da localização comercial. Numa cidade onde as avenidas convergem para um único centro, haverá a atração para este ponto de grande parte das atividades terciárias ${ }^{10}$. Assim, podemos considerar que algumas atividades comerciais têm como estratégia de localização a presença regular do público que, com outros objetivos que não a compra, passa por determinados lugares. Mas esta é apenas uma das "cenas" urbanas propícias ao comércio.

O comércio urbano, como já mencionado, tem sua localização condicionada pelos diversos tipos de relevo do sítio natural. Esses tipos da geomorfia urbana condicionam não apenas as modalidades de deslocamentos (a pé, automóvel, transporte coletivo etc.), como também os ângulos de visada. Tanto as modalidades de deslocamento quanto as visadas orientam a localização das atividades: umas se beneficiam do público passante, que se desloca a pé, outras buscam pontos de maior visibilidade a grandes distâncias. Como mostra Kohlsdorf (1996, p. 136), a observação de lugares, a apreensão de partes da cidade são serial visions, ou lugares percebidos a partir do ponto de vista de quem nele se desloca. Também Cullen (1961) enfatiza os atributos cinéticos da configuração espacial percebida por quem se movimenta. Isso porque, ainda de acordo com Kohlsdorf (1996, p. 84), o campo visual é caracterizado por três zonas perceptivas: espaço primário ("o lugar que o observador ocupa em seu campo visual"), secundário ("coincidente com o canal de deslocamento do observador e definido pelas superfícies que delimitam o percurso, como fachadas muros e taludes"); e terciário ("ligado à paisagem circundante e definido por elementos diversos da mesma, como silhuetas, bosques e linhas de cumeada").

Como o movimento e o modo de locomoção do observador determinam as condições de seus campos visuais, as maiores velocidades correspondem a menores ângulos de visão. Nesta situação, a atenção se fixa em pontos adiante, nos elementos mais distantes e aparentemente mais estáticos do que aqueles que, pela velocidade do deslocamento, se mostram na rápida sucessão. Assim, uma cidade, com formas de relevo singulares e suas correspondentes modalidades de deslocamento, apresentará características próprias, distinguindo-se de outras quanto à distribuição dos usos não-residenciais em geral e, em particular, do comércio urbano. Uma cidade rica em formas de relevo, como Belo Horizonte, propicia o exame de várias ocorrências da localização das atividades de comércio relacionada e seus condicionantes físicos. Foi proposta uma tipificação ${ }^{11}$ da figuras de relevo como subsídio para a elaboração da Lei de Uso e Ocupação do Solo de 1976 para Belo Horizonte, que teve como resultado os seguintes casos e seus correspondentes conteúdos paisagísticos ou características percebidas:

- Área plana - baixa declividade; visibilidade, acessibilidade e características percebidas sem destaque frente aos outros tipos.

- Vale contínuo - baixa declividade; alta visibilidade, alta acessibilidade; espaço percebido como côncavo, convergente e centrípeto.

- Vale curto ou grota - declividade baixa e ascendente no final; visibilidade alta ou média; baixa acessibilidade; espaço percebido como côncavo, convergente e centrípeto.

- Crista contínua ou linha de cumeada - declividade variável predominantemente baixa; alta visibilidade; alta acessibilidade; espaço percebido como convexo, visualmente convergente e fisicamente divergente.

- Crista curta ou espigão - declividade média e no topo baixa; alta visibilidade; acessibilidade média ou alta; espaço percebido como convexo, visualmente convergente e fisicamente divergente.

- Sela ou colo - baixa declividade em pequeno trecho; alta e média visibilidade; acessibilidade alta; espaço percebido como côncavo/convexo, convergente/divergente, centrípeto/centrífugo. 
- Encosta - declividade variável; baixa visibilidade; acessibilidade variável; espaço percebido como divergente e centrífugo.

Alguns pontos da cidade são mais vistos que outros. Outros não têm tanta visibilidade, mas para o tipo de atividade que acolhem é suficiente uma boa possibilidade de caminhada a pé. Para cada caso, há uma loja e um lojista atento ao que melhor the convém. As estratégias de localização devem variar muito, dependendo do comportamento do potencial cliente. Se o potencial cliente chegará de fato a "entrar na loja", vai depender de uma "atualização" de sua "agenda de compras". Esta "agenda" não existe em lugar nenhum a não ser como uma (vaga) lembrança de que é preciso comprar, por exemplo, conectores para cabos elétricos ou um suporte para CDs. A atualização da agenda vai acontecer, por exemplo, no contato visual com a loja de material elétrico, ao passar a $70 \mathrm{~km} / \mathrm{h}$, dirigindo o automóvel pela via coletora, com declividade variando de 5 a 10\%, que conduz às vicinais onde mora o potencial comprador. Este "agendamento" é um momento do processo da compra do objeto desejado. Neste cenário, combinam-se declividade, velocidade e possibilidade de convergência visual. Outros cenários com outros componentes existem e serão tão mais diversificados quanto maior for o número das figuras de relevo - ou das figuras geomórficas - presentes em uma cidade.

As "agendas" são muitas. Necessidades mais prementes (comprar um analgésico ou um vinho para uma visita inesperada) e necessidades nem tão urgentes (levar a calça jeans para a loja de reformas de roupas) têm agendas diferentes. "Agendas", conforme aqui consideradas, não são catálogos de necessidades, mas a ativação da lembrança da necessidade mediante a "leitura" de um ponto muito específico da cidade. A "leitura" não se restringe ao contato visual (ver a placa da loja para saber que ali existe tal atividade), mas também implica a avaliação de outra modalidade de deslocamento: quem viu a placa da loja ao passar de automóvel pode vir depois andando a pé. Assim, as modalidades de deslocamento (andar a pé, de automóvel, de ônibus ou de metrô), cada uma isoladamente ou a combinação delas, definem suportes cênicos específicos ${ }^{12}$. $\bigcirc$ "cenário urbano", como se vê, não é apenas o invólucro das atividades urbanas, mas a ativação de predisposições, "atualização", envolvendo a combinação de atividades físicas ${ }^{13}$.

No debate recente sobre a conveniência de se legislar sobre a localização das atividades na cidade a complexidade do tema desaparece no isolamento das várias áreas especializadas que se ocupam da questão urbana. Muitas vezes o debate é interrompido frente a um impasse que na verdade é uma questão mal colocada: devem-se criar zonas de comércio ou as forças de mercado impulsionam as atividades para as localidades mais desejáveis para toda cidade? A questão não é muito simples e requer posturas alternativas. Uma delas poderia começar com a desconfiança de que não existem generalizações fáceis e que sirvam para grande número de casos. Apenas o exame minucioso de cada cidade, com suas variadas figuras de relevo, garante o conhecimento de todos os componentes apropriados para a localização comercial. Forças centrípetas ou centrífugas caracterizando cenários que nos repelem ou nos aproximam, visadas permitindo convergência ou divergência visual, são as possibilidades dadas pelas conformações côncavas ou convexas de algumas figuras de relevo. Como esboço de conclusão pode-se afirmar que, se os acidentes geográficos fazem a singularidade (o caráter, a alma, a personalidade) da cidade, não há como superpor a ela o esquema redutor de um modelo na pretensão de esgotar toda sua dinâmica. 


\section{Notas}

(1) Este trabalho é uma seção de um marco teórico para um projeto de pesquisa conduzida pelo autor, com o título "Planos Diretores e Leis de Uso e Ocupação do Solo como indutores da distribuição da densidade urbana: indicações para uma avaliação em Belo Horizonte"

(2) Por "elemento" de um sistema, entendem-se as partes ou componentes que o constituem; estas podem se referir a objetos ou processos. Uma vez identificados, os elementos podem se organizar em um "modelo" ou representações orientadas, conduzidas para fins a priori definidos de um sistema.

(3) Ao contrário do que poderia se pensar, "diversidade", na edição brasileira recente do livro de Jane Jacobs, não é uma tradução forçada, uma introdução indevida de um vocábulo que aparentaria um aggiornamento, uma concessão a um modismo, para fazer de um livro, escrito há mais de quarenta anos atrás, um alvo para os caçadores ávidos do que há de mais novo sobre cidades.

(4) A idéia de "diversidade" ganha outra dimensão em trabalhos mais recentes da autora; um sentido ainda não de todo explicitado em "Morte e vida das grandes cidades", mas que aparece no seu livro A natureza das economias, no qual "diversidade" aplicada na consideração das cidades se aproxima da idéia de "sinergia". Considera-se um sistema "sinergético" aquele que apresenta um fenômeno resultante da interação de suas partes, onde a totalidade é a conservação do todo na ação recíproca das partes, onde o todo é maior que a soma de elementos isolados. Quanto à consideração da localização do comércio urbano, trata-se de uma abordagem imprescindível para a análise do fenômeno de atratividade de umas atividades comerciais sobre outras e a dependência mútua entre atividades atratoras e atraídas.

(5) "Renda da terra são juros de um capital imaginário", de acordo com expressão de Karl Marx. Isso significa que o preço de uma gleba é função da renda, do aluguel que ela proporciona.

(6) A rigor, "produtividade" não é um conceito apropriado para se falar do terciário em geral, mas aqui restringimos "produtividade" à possibilidade de ganhos acima do lucro médio no comércio urbano. Para a teoria marxista, "produtividade" relaciona-se apenas ao capital que gera a mais-valia, o sobre-trabalho - que é a fonte de todo o conjunto do lucro; enquanto o comércio é "improdutivo", ou seja, a geração do lucro social não está nele, embora ele possa acelerar a formação das taxas gerais de lucro. Para a teoria da distribuição de Karl Marx, o lucro total gerado nos setores produtivos (indústria e agricultura) é distribuído ainda na forma de juros para o capital bancário e como renda fundiária para os proprietários de terras.

(7) Esta adaptação da teoria da localização agrícola para a localização urbana pode ser acompanhada em Singer (1979) - o autor, com o conceito de "velocidade de vendas", trata da "rotação do capital", processo no qual a determinação da lucratividade diferenciada entre capitais de montantes iguais depende da velocidade do retorno do capital adiantado; sobre esse tema, ver também o livro II de O capital, de Karl Marx.

(8) Os modelos de localização têm como pressuposto a homogeneidade da superfície urbana, onde o espaço é livre de acidentes geográficos; ver POLESE (1998), p. 326.

(9) As características singulares, únicas para cada cidade, dão a ela sua "personalidade" que a difere de outras. Em geral, tais singularidades são dadas pelas características naturais, físicas, do sítio natural. Aqui podemos fazer uma aproximação conhecida pela cultura filosófica, na qual se associa "matéria" ao suporte das singularidades e "forma" ao universal. Modelos, conforme discutido acima, têm o caráter de universalidade (são "universaisempíricos") e deixam escapar as singularidades.

(10) Um exemplo de localização comercial numa estrutura radiocêntrica é Belo Horizonte, que tem mais de $60 \%$ de suas atividades terciárias na zona central, conforme Amaro (1994). Outras estruturas que têm modos peculiares de distribuição das atividades terciárias são aquelas em "tabuleiro", onde o traçado viário é formado por vias ortogonais; e aquelas estruturas muito conhecidas em cidades litorâneas onde o desenvolvimento é linear. Ambas, ao contrário das radiocêntricas, tendem a dispersar a distribuição comercial e apresentam rápida obsolescência semântica dos centros comerciais, dada a migração de centros para pontos da cidade onde se divulga, alardeia, como a localização mais "moderna".

(11) Esta tipificação, elaborada no PLAMBEL (Superintendência da Região Metropolitana de Belo Horizonte), constitui hoje um trabalho de referência sobre localização de atividades relacionada com as formas do relevo (RIBEI$\mathrm{RO}, 1975)$.

(12) Por não levar em conta essas diferenças, os planos urbanísticos muitas vezes reservam áreas para comércio em lugares estéreis, sem futuro para pontos de vendas. Um exemplo está em Belo Horizonte, na rua Platina, onde, no início da ocupação, as paradas do bonde e, posteriormente, de ônibus pontuaram toda sua extensão com atividades terciárias. Os técnicos de planejamento da cidade devem ter pensado que o mesmo aconteceria com a presença do metrô e reservaram espaço para novas lojas, mas o resultado foi aridez, lojas fechadas, contrastando com as antigas paradas de bonde, atestando o desconhecimento das diferenças fundamentais entre modalidades de deslocamentos.

(13) Procura-se aqui refletir sobre o espaço vivenciado, conforme as pesquisas da fenomenologia, particularmente através do capítulo "O Espaço" do livro Fenomenologia da percepção, de Merleau-Ponty; e ainda das noções de "intenção" (Meinung) e "preenchimento" (Erfüllung) de Husserl, conforme comentários de Fragata (1959). 


\section{Bibliografia}

AMARO, João Júlio Vitral. Städtischer Bodenmarkt und Urbanisierung in Belo Horizonte - ein Beispiel für die Entwicklung in Brasilien. Berlin: Verlag fuer Wissenchaft und Forschung, 1994.

CULLEN, Gordon. Townscape. Londres: The Architectural Press, 1961.

FRAGATA, Júlio. A fenomenologia de Husserl como fundamento da Filosofia. Braga: Editora Livraria Cruz, 1959.

JACOBS, Jane. A natureza das economias. São Paulo: Editora Beca, 2001.

. The death and life of great American cities. Nova York: Penguin, 1961.

KOLHSDORF, Maria Elaine. A apreensão da forma da cidade. Brasília: Editora UnB, 1996.

MARX, Karl. O capital. São Paulo: Abril, 1983.

MERLEAU-PONTY, Maurice. Fenomenologia da percepção. Rio de Janeiro: Editora Livraria Freitas Bastos, 1971.

POLĖSE, Mario. Economía Urbana y Regional - introducción a la relación entre território y desarrollo. Cartago: Editorial Tecnológica de Costa Rica, 1998.

RIBEIRO, Maurício Andrés. Notas sobre o corpo urbano de Belo Horizonte. Revista Fundação João Pinheiro, v. 5 n. 4 , abr. 1975.

SINGER, Paul. O uso do solo na economia capitalista. In: MARICATO, E. A produção capitalista da casa e da cidade no Brasil industrial. São Paulo: Editora Alfa-Omega, 1979. p. 21-104.

VON THÜNEN, Johann Heinrich. Der Isolierte Staat in Beziehung zur Nationalökonomie und Landwirtschaft. Hamburg; 1826. 